Article

\title{
Interaction between Microalloying Additions and Phase Transformation during Intercritical Deformation in Low Carbon Steels
}

\author{
Unai Mayo ${ }^{1,2}$, Nerea Isasti ${ }^{1,2}$, Jose M. Rodriguez-Ibabe ${ }^{1,2}$ and Pello Uranga $1,2, * \mathbb{D}$ \\ 1 Materials and Manufacturing Division, CEIT, 20018 San Sebastian, Basque Country, Spain; \\ umayo@ceit.es (U.M.); nisasti@ceit.es (N.I.); jmribabe@ceit.es (J.M.R.-I.) \\ 2 Mechanical and Materials Engineering Department, Universidad de Navarra, Tecnun, \\ 20018 San Sebastian, Basque Country, Spain \\ * Correspondence: puranga@ceit.es; Tel.: +34-943-212-800
}

Received: 29 August 2019; Accepted: 25 September 2019; Published: 27 September 2019

\begin{abstract}
Heavy gauge line pipe and structural steel plate materials are often rolled in the two-phase region for strength reasons. However, strength and toughness show opposite trends, and the exact effect of each rolling process parameter remains unclear. Even though intercritical rolling has been widely studied, the specific mechanisms that act when different microalloying elements are added remain unclear. To investigate this further, laboratory thermomechanical simulations reproducing intercritical rolling conditions were performed in plain low carbon and $\mathrm{NbV}$-microalloyed steels. Based on a previously developed procedure using electron backscattered diffraction (EBSD), the discretization between intercritically deformed ferrite and new ferrite grains formed after deformation was extended to microalloyed steels. The austenite conditioning before intercritical deformation in the $\mathrm{Nb}$-bearing steel affects the balance of final precipitates by modifying the size distributions and origin of the $\mathrm{Nb}(\mathrm{C}, \mathrm{N})$. This fact could modify the substructure in the intercritically deformed grains. A simple transformation model is proposed to predict average grain sizes under intercritical deformation conditions.
\end{abstract}

Keywords: intercritical rolling; microalloying; microstructure; EBSD

\section{Introduction}

Intercritical rolling is extensively employed in the production of heavy gauge structural plates, with the aim of meeting the increasing material demands of a variety of structural applications. Rolling in the austenite/ferrite two-phase region has already been explored for plain carbon steels [1]. However, the effect of intercritical rolling for microalloyed steels is less investigated [2]. Therefore, a deeper understanding of the microstructural evolution under intercritical conditions and the influence of different austenite-ferrite balances at high temperature is required for microalloyed steels in order to define stable processing windows. It is well established that the addition of $\mathrm{Nb}$ as an alloying element can retard or inhibit the recrystallization of austenite and ferrite due to two mechanisms: the solute drag effect related to $\mathrm{Nb}$ in solid solution and the pinning effect caused by strain-induced precipitation [3].

In intercritical rolling, several microstructural mechanisms could be activated, such as restoration and recrystallization. The recovery and recrystallization phenomena occurring during deformation in the two-phase region has been extensively analyzed for CMn steels [4,5]. It is well known that the restoration process taking place during or after the intercritical deformation could be affected by the available niobium during austenite to ferrite transformation. However, the interaction between $\mathrm{Nb}$ 
in solution and softening kinetics is less explored in the intercritical region [2,6]. Therefore, a deeper understanding is needed regarding this issue.

In a recently published work [7], the microstructural evolution during intercritical deformation was explored for low carbon steels, and a methodology capable of differentiating different ferrite populations (intercritically deformed and non-deformed ferrite formed during the final cooling) using EBSD was developed. This methodology will provide a better understanding of the exact effect of the rolling process parameters on each ferrite population. For this purpose, intercritical deformation simulations were carried out via dilatometry tests using CMn steels with different $C$ content, and an exhaustive EBSD characterization procedure was developed to classify and quantify the different phases obtained after air cooling [7]. The procedure can be summarized in two steps. First, pearlite has to be removed from the calculations, and to that end, the grain average image quality (IQ) parameter is used $[7,8]$. Taking into account that pearlite is of a lower quality than ferrite, the lowest IQ value points are removed. The removed fraction from EBSD scans are close to the pearlite contents measured by optical microscopy. Then, using the grain orientation spread (GOS) parameter, which is the average deviation between the orientation of each point in the grain and the average orientation of the grain, the remaining ferrite grains are separated in two populations: DF (deformed ferrite) and NDF (non-deformed ferrite). This differentiation will allow for a better understanding of the effect of the different parameters and processes, such as restoration, precipitation etc., that occur during intercritical deformation for each NDF and DF family. It is assumed that during deformation, a distortion in the crystal lattice is introduced, leading to higher GOS parameter values [7,9]. Therefore, the GOS parameter distribution is strongly affected by the ferrite content prior to intercritical deformation. In the recently published work, a GOS value of $2^{\circ}$ was set to differentiate NDF from DF, yielding reasonable results. This procedure was developed for polygonal ferritic microstructures transformed from fine austenitic structures. However, in the current work, slightly different intercritically deformed microstructures were formed due to the addition of microalloying elements. Depending on the austenite condition and chemical composition, different ferrite morphology could be achieved. Coarser austenite grains, as well as addition of microalloying elements, promote the delaying of phase transformation, leading to the formation of more non-polygonal transformation products [10,11]. In this study, given that more bainitic phases, such as quasi-polygonal ferrite, are observed, differentiating non-deformed and deformed ferrite grains becomes more complex. Therefore, the threshold able to distinguish non-deformed ferrite from deformed ferrite (previously shown in [7]) has to be redesigned.

The current work shows the complex interaction between austenite-ferrite content prior to deformation, microalloying elements, austenite condition (recrystallized and deformed austenite) and microstructural evolution during intercritical rolling. To that end, intercritical deformation simulations were performed in a deformation dilatometer for $\mathrm{CMn}$ and $\mathrm{NbV}$-microalloyed steels. In addition to obtaining microstructural characterization by means of conventional characterization techniques (optical and electron microscopy), a precipitation analysis was also performed for the $\mathrm{NbV}$-microalloyed steel.

\section{Materials and Methods}

The chemical compositions of the steels are listed in Table 1 . The materials were laboratory cast and hot-rolled to $16 \mathrm{~mm}$-thick plates/slabs.

Table 1. Chemical composition of the studied steels (weight percent).

\begin{tabular}{cccccccccc}
\hline Steels & $\mathbf{C}$ & $\mathbf{M n}$ & $\mathbf{S i}$ & $\mathbf{C r}$ & $\mathbf{V}$ & $\mathbf{T i}$ & $\mathbf{A l}$ & $\mathbf{N b}$ & $\mathbf{N}$ \\
\hline $\mathrm{CMn}$ & 0.063 & 1.53 & 0.25 & 0.012 & 0.005 & 0.002 & 0.035 & 0.002 & 0.003 \\
$\mathrm{NbV}$ & 0.062 & 1.52 & 0.25 & 0.012 & 0.034 & 0.002 & 0.038 & 0.056 & 0.004 \\
\hline
\end{tabular}

Uniaxial compression tests, depicted schematically in Figure 1, were performed using a Bähr DIL805D deformation dilatometer (BÄHR Thermoanalyse GmbH, Hüllhorst, Germany). Solid cylinders 
of $5 \mathrm{~mm}$ in diameter and $10 \mathrm{~mm}$ in length were used. Two different thermomechanical schedules were defined with the purpose of obtaining different austenite conditions (recrystallized and deformed austenite, in Cycle A and Cycle B, respectively) prior to transformation. As shown in Figure 1, both schedules include a solubilization treatment at $1250{ }^{\circ} \mathrm{C}$ for $15 \mathrm{~min}$ to ensure the total dissolution of $\mathrm{Nb}$ and $\mathrm{V}$ precipitates. Afterwards, a multipass deformation sequence was designed. Both cycles include a deformation of 0.4 at $1050{ }^{\circ} \mathrm{C}$, in order to ensure a fine recrystallized austenite. In Cycle B, a second deformation pass is applied at $900^{\circ} \mathrm{C}$, below the non-recrystallized temperature, in order to obtain a deformed austenite prior to transformation. Cycle A was applied to the CMn steel, whereas both schedules were applied to the $\mathrm{NbV}$ microalloyed steel. The samples were cooled down slowly $\left(1{ }^{\circ} \mathrm{C} / \mathrm{s}\right)$ to three different deformation temperatures (Tdef25, Tdef50, and Tdef75), in order to obtain three ferrite fractions $(25 \%, 50 \%$, and $75 \%$ ) before the intercritical deformation. Finally, a deformation of 0.4 was applied in the intercritical region. After that, the specimens were cooled down to room temperature $\left(1^{\circ} \mathrm{C} / \mathrm{s}\right)$ in both steels.

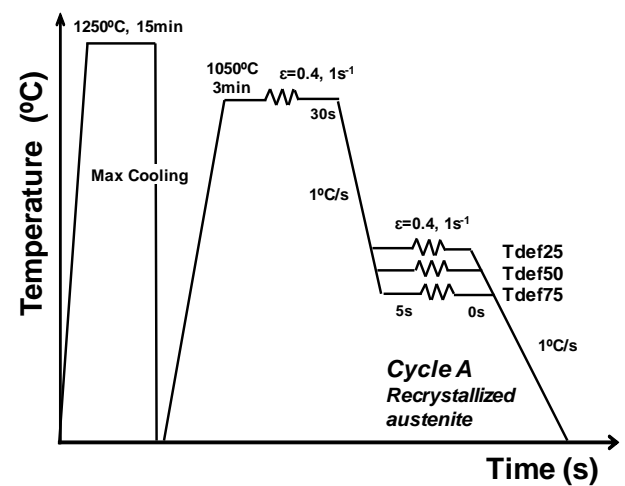

(a)

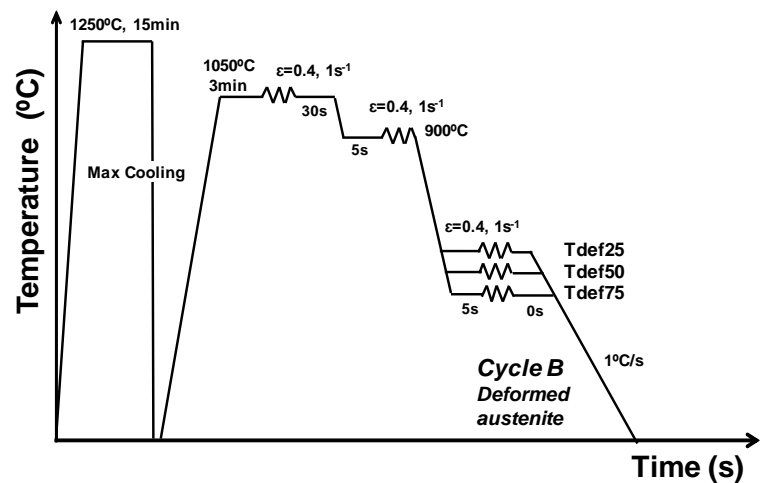

(b)

Figure 1. Thermomechanical schedule performed in the dilatometer: (a) CMn steel and NbV-microalloyed steel; (b) NbV-microalloyed steel only.

The deformation temperatures for achieving the predefined $25 \%, 50 \%$, and $75 \%$ ferrite fractions were determined based on the dilatometry curves. The lever rule was considered in defining the evolution of transformed ferrite fraction and proportionality between transformed fraction and measured sample length change was assumed. The lever rule is based on extrapolating the linear expansion behavior from the temperature regions where no transformation occurs and subsequently assuming proportionality between the fraction of decomposed austenite and the observed length change [12]. The ferrite fractions prior to deformation were measured in each deformation temperature by systematic manual point count [13].

The dilatometry samples for the corresponding microstructural characterization were prepared according to the following procedure. First, the selected samples were cut along their longitudinal axis, at the region corresponding to a maximum area fraction of nominal strain and reduced strain gradient [14]. After that, the samples were mechanically grounded with $\mathrm{SiC}$ abrasive papers and polished with different diamond paste grades $(6,3$, and $1 \mu \mathrm{m})$ to get mirror surfaces. Finally, the samples were etched with a $2 \%$ Nital solution. The microstructures were analyzed using different characterization techniques like optical microscopy (OM, LEICA DMI5000 M, Leica Microsystems, Wetzlar, Germany) and field-emission gun scanning electron microscopy (FEG-SEM, JEOL JSM-7000F, JEOL Ltd., Tokyo, Japan).

In order to evaluate the crystallographic features of the dilatometry tests in more detail, EBSD scans were performed for all cases. For that purpose, samples were polished with a colloidal silica suspension. Orientation imaging microscopy was performed on the Philips XL 30CP SEM with W-filament using TSL (TexSEM Laboratories, UT, USA) equipment. The total scanned area of the 
EBSD mappings was $350 \times 350 \mu \mathrm{m}^{2}$, using a step size of $0.5 \mu \mathrm{m}$ and an accelerating voltage of $20 \mathrm{kV}$. The scans were analyzed using TSL OIM ${ }^{\mathrm{TM}}$ Analysis 5.31 software (EDAX, Mahwah, NJ, USA). During the post-processing, a clean-up procedure was applied to the raw data obtained from the scans to assimilate any non-indexed points into the surrounding neighborhood grains. A single iteration dilation clean-up routine with a tolerance angle of $5^{\circ}$ and a minimum size of 3 pixels was defined. In addition, the neighbor $\mathrm{CI}$ correlation procedure was taken into account, defining 0.1 as the minimum accepted value. If there was any point with a CI value lower than 0.1 , the orientation and $\mathrm{CI}$ of the particular point were reassigned to match the orientation and $\mathrm{CI}$ of the neighbor with the maximum CI.

The size and morphology of the precipitates were studied by TEM on a scanning transmission electron microscope JEOL JEM 2100 (TEM, JEOL 2100, JEOL Ltd., Tokyo, Japan) operated at 200 kV. Carbon extraction replicas were obtained from dilatometry samples. Copper grids were employed to support the carbon replicas.

\section{Results and Discussion}

\subsection{Definition of Deformation Temperatures}

In Figure 2a, the dilation curves obtained during air cooling are plotted for both steels and austenite conditions, represented as $\Delta \mathrm{L} / \mathrm{L} 0$ as a function of temperature. Figure $2 \mathrm{~b}$ illustrates the evolution of the transformed ferrite fraction for $\mathrm{CMn}, \mathrm{NbV}$-recrystallized austenite, and $\mathrm{NbV}$-deformed austenite (these curves are obtained from the dilatometry curves shown in Figure 2a). In Figure 2b, the desired fractions of ferrite $(25 \%, 50 \%$, and $75 \%)$ are also drawn. As Figure 2 shows, depending on the chemical composition, the transformation temperature varies. Given the aim of generating different ferrite contents of approximately $25 \%, 50 \%$, and $75 \%$, deformation temperatures of 750,740 , and $730{ }^{\circ} \mathrm{C}$ were selected for the $\mathrm{CMn}$ steel. Meanwhile, for the $\mathrm{NbV}$ steel, the formation of different fractions of ferrite were achieved at deformation temperatures of 750, 730, and $720^{\circ} \mathrm{C}$ in Cycle A and 770, 750, and $740{ }^{\circ} \mathrm{C}$ in Cycle B (Tdef25, Tdef50, and Tdef75, respectively).

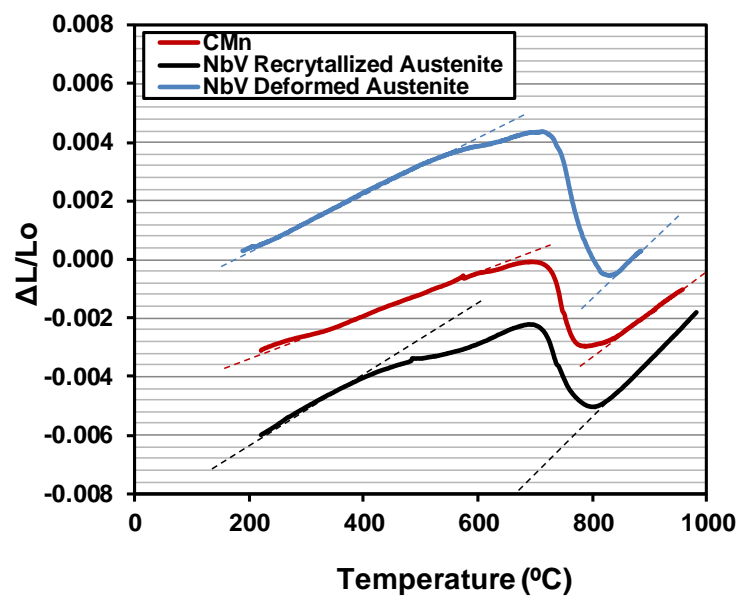

(a)

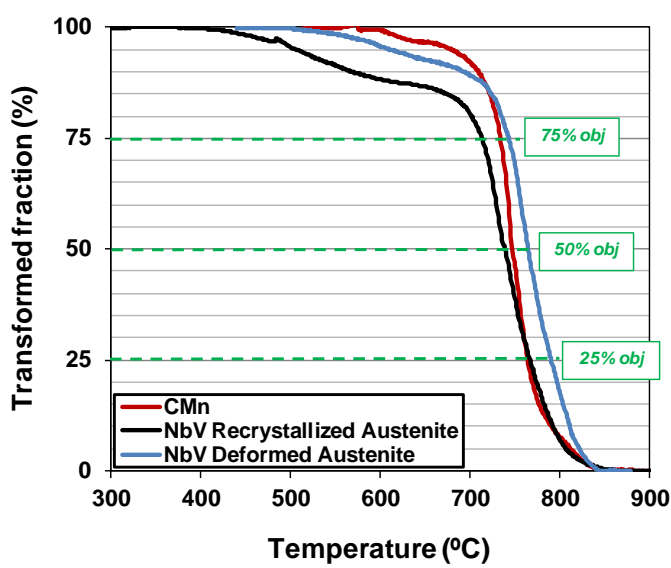

(b)

Figure 2. (a) Dilation curves and (b) evolution of transformed fraction in both steels and both austenite conditions for the $\mathrm{NbV}$ steel.

Using the deformation temperatures predicted in the dilatometry study as a reference, several interrupted quenching tests were performed to check that the ferrite content formed at those temperatures agreed with the objective ferrite fractions. Figure 3 shows the quenched microstructures obtained before different intercritical deformation temperatures for CMn steel (no deformation is applied in the austenite-ferrite domain). In Figure 4, the microstructures corresponding to $\mathrm{NbV}$ quenched specimens before intercritical deformation are shown for both austenite conditions and the 
entire range of deformation temperatures. The microstructures shown in Figures 3 and 4 illustrate the variation of the ferrite-martensite balance caused by the modification of deformation temperature, where more ferrite is formed as the temperature decreases. Together with the microstructure, the measured ferrite fraction is also noted in all cases. All these data are summarized in Table 2.

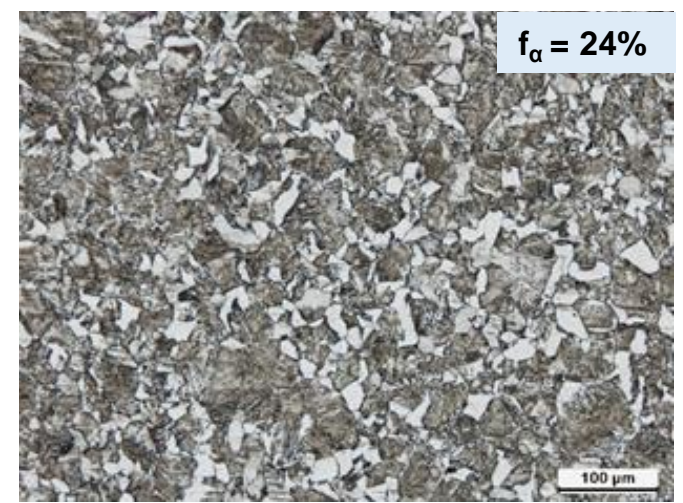

(a) Tdef $25750{ }^{\circ} \mathrm{C}$

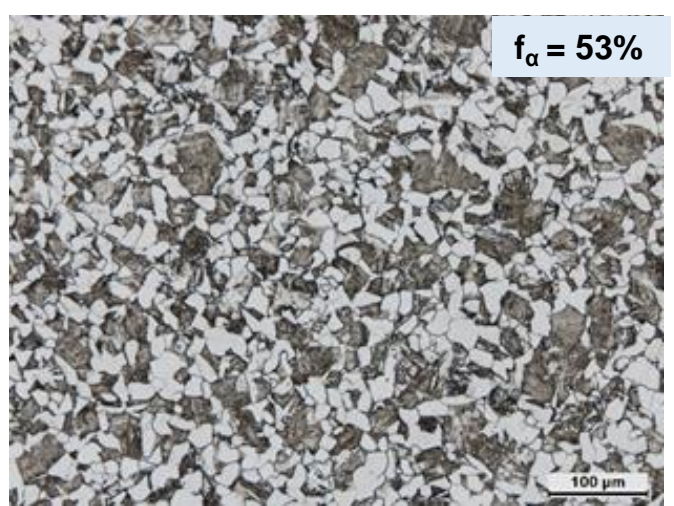

(b) Tdef50 $740{ }^{\circ} \mathrm{C}$

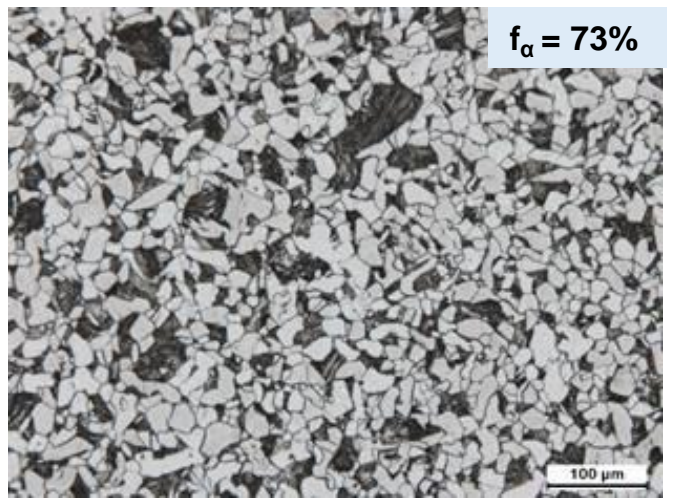

(c) Tdef75 $730{ }^{\circ} \mathrm{C}$

Figure 3. Optical micrographs obtained after a quenching at different deformation temperatures and CMn steel (before intercritical deformation): (a) Tdef25, (b) Tdef50, and (c) Tdef75.

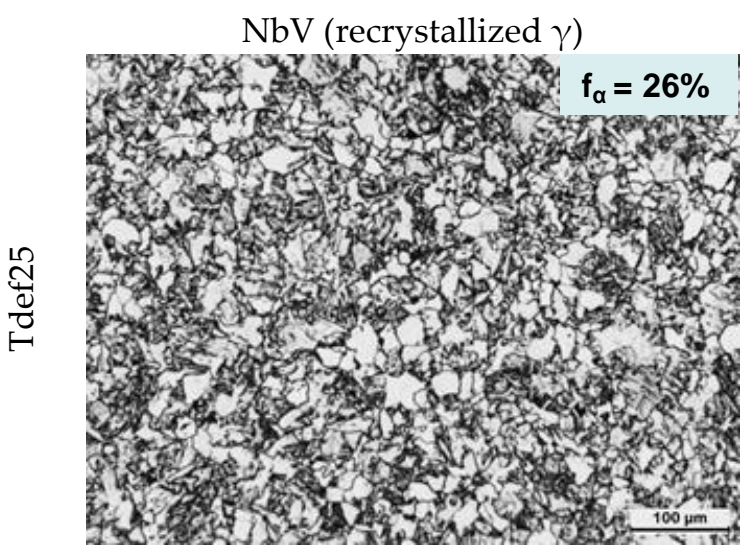

(a) Tdef25 $750{ }^{\circ} \mathrm{C}$

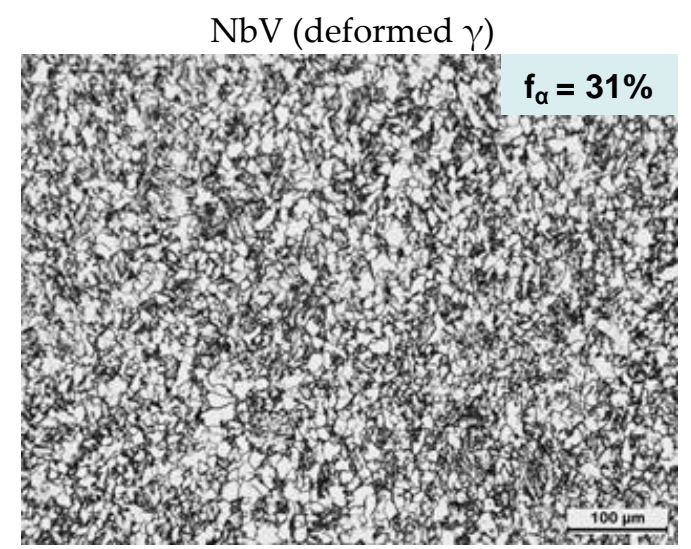

(d) Tdef25 $770{ }^{\circ} \mathrm{C}$

Figure 4. Cont. 


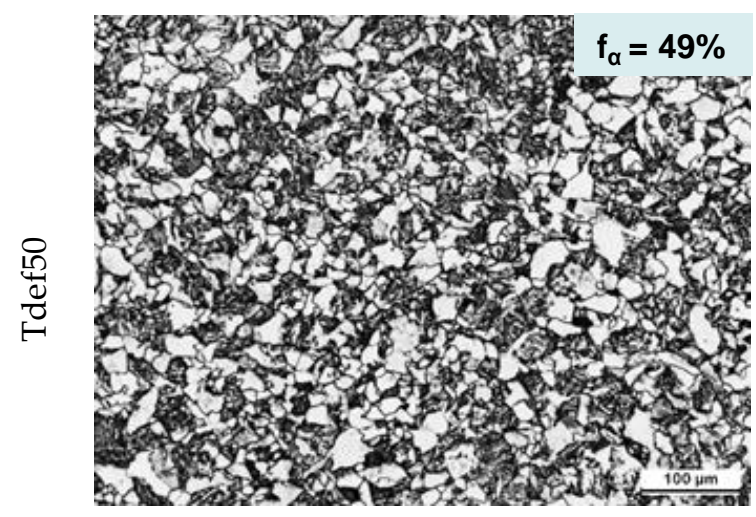

(b) Tdef50 $730{ }^{\circ} \mathrm{C}$

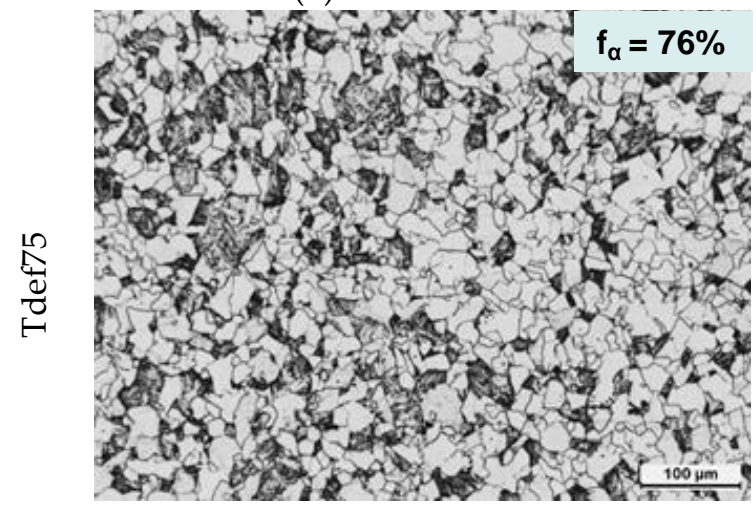

(c) Tdef75 $720{ }^{\circ} \mathrm{C}$

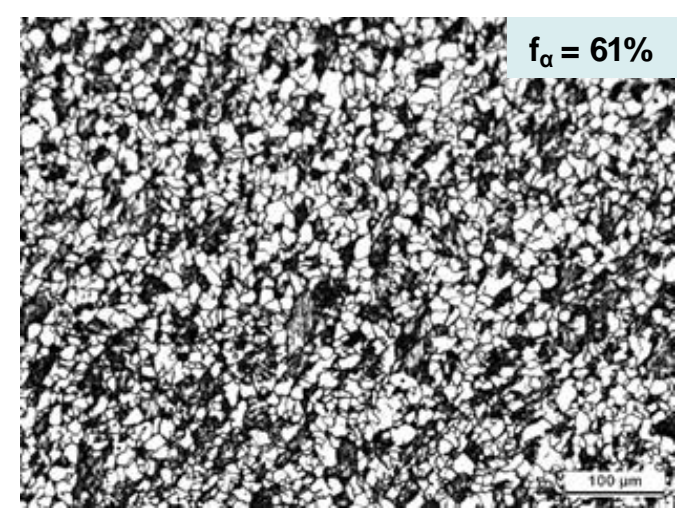

(e) Tdef50 $750{ }^{\circ} \mathrm{C}$

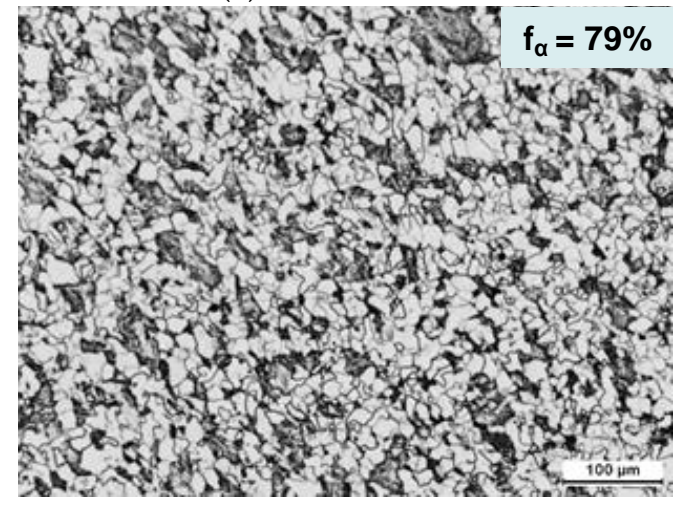

(f) $\mathrm{Tdef} 75740{ }^{\circ} \mathrm{C}$

Figure 4. Optical micrographs obtained after a quenching at different deformation temperatures (before intercritical deformation) and both austenite conditions for $\mathrm{NbV}$-microalloyed steel (recrystallized and deformed): (a,d) Tdef25, (b,e) Tdef50, and (c,f) Tdef75.

Table 2. Measured ferrite fraction in each deformation temperature, both chemical compositions, and austenite conditions after quenching.

\begin{tabular}{cccccccc}
\hline \multirow{2}{*}{$\begin{array}{c}\text { Steel and Austenite } \\
\text { Condition }\end{array}$} & \multicolumn{2}{c}{$\mathbf{2 5 \%}$ Ferrite } & \multicolumn{2}{c}{$\mathbf{5 0 \%}$ Ferrite } & \multicolumn{2}{c}{$\mathbf{7 5 \%}$ Ferrite } \\
\cline { 2 - 7 } & $\begin{array}{c}\text { Tdef25 } \\
\left({ }^{\circ} \mathbf{C}\right)\end{array}$ & $\begin{array}{c}\text { Measured } \\
\mathbf{f} \boldsymbol{\alpha}\end{array}$ & $\begin{array}{c}\text { Tdef50 } \\
\left({ }^{\circ} \mathbf{C}\right)\end{array}$ & $\begin{array}{c}\text { Measured } \\
\mathbf{f} \boldsymbol{\alpha}\end{array}$ & $\begin{array}{c}\text { Tdef75 } \\
\left({ }^{\circ} \mathbf{C}\right)\end{array}$ & $\begin{array}{c}\text { Measured } \\
\mathbf{f} \boldsymbol{\alpha}\end{array}$ \\
\hline $\mathrm{NbV}$ & $\begin{array}{c}\text { Cycle A } \\
\text { recrystallized } \gamma \\
\text { Cycle B } \\
\text { deformed } \gamma \\
\text { Cycle A }\end{array}$ & 750 & $26 \%$ & 730 & $49 \%$ & 720 & $76 \%$ \\
$\mathrm{CMn}$ & 750 & $31 \%$ & 750 & $61 \%$ & 740 & $79 \%$ \\
\hline
\end{tabular}

For $\mathrm{NbV}$ steel (see Figure 4), a microstructural refinement (finer ferrite grains) is observed when the transformation occurs from deformed austenite (Cycle B). This refinement is related to the increase in the density of nucleation sites introduced by deformation in the austenite [11]. The ferrite fractions prior to deformation were measured in each deformation temperature and the results are presented in Table 2. As shown in Table 2, the measured ferrite fractions are very close to the objective ones.

\subsection{Microstructures at Room Temperature after Intercritical Deformation}

In Figure 5, optical micrographs corresponding to room temperature after intercritical deformation for both steels (CMn and $\mathrm{NbV}$ ) and both austenite conditions (recrystallized in Cycle A and deformed austenite in Cycle B) are presented. Combinations of non-deformed ferrite (NDF) and deformed ferrite (DF) are clearly distinguished in all the cases. Moreover, the formation of pearlite is observed in the 
resulting microstructures. Pearlite fractions of $13.7 \%, 6.1 \%$, and $6.2 \%$ have also been measured for $\mathrm{CMn}, \mathrm{NbV}$ recrystallized austenite, and $\mathrm{NbV}$ deformed austenite Tdef2 5 samples, respectively. In both chemical compositions (see Figure 5), the fraction of deformed ferrite increases as the deformation temperature decreases, due to a higher amount of ferrite formed prior to the intercritical deformation. This deformed ferrite is characterized by a significant presence of substructure (see Figure 5c), reflecting the fact that ferrite is restored after deformation in the intercritical region [6]. In addition, the morphology of non-deformed ferrite changes from a polygonal ferrite (see Figure 5d) to a quasi-polygonal ferrite (non-equiaxed) as deformation temperature decreases (see Figure 5f).

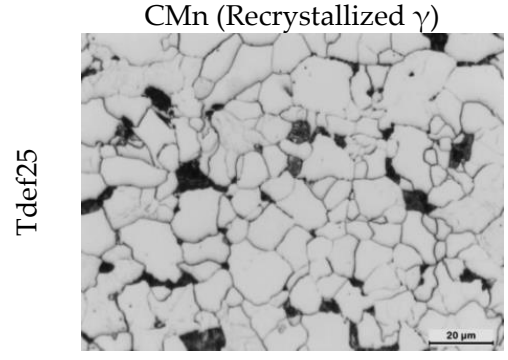

(a) $\operatorname{Tdef} 25750{ }^{\circ} \mathrm{C}$

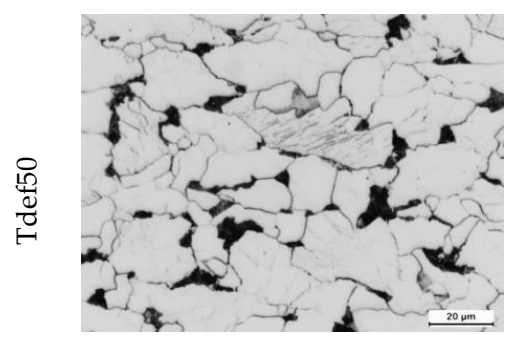

(b) $\operatorname{Tdef} 50740{ }^{\circ} \mathrm{C}$

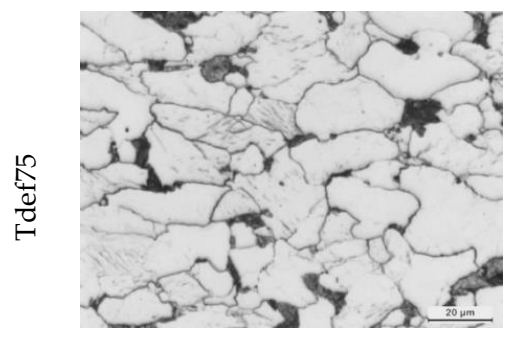

(c) $\operatorname{Tdef} 75730^{\circ} \mathrm{C}$

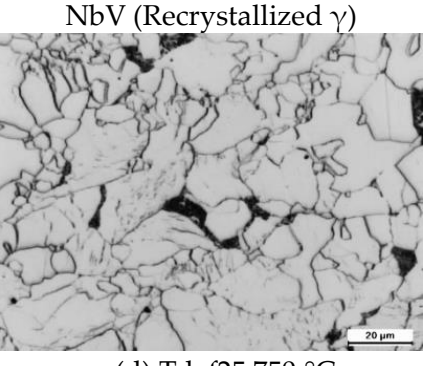

(d) Tdef $25750{ }^{\circ} \mathrm{C}$

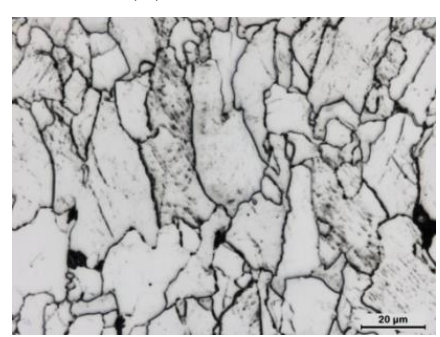

(e) Tdef50 $730{ }^{\circ} \mathrm{C}$

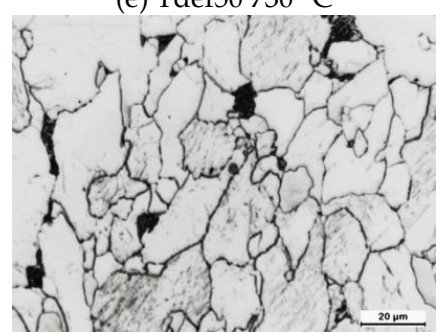

(f) Tdef75 $720^{\circ} \mathrm{C}$

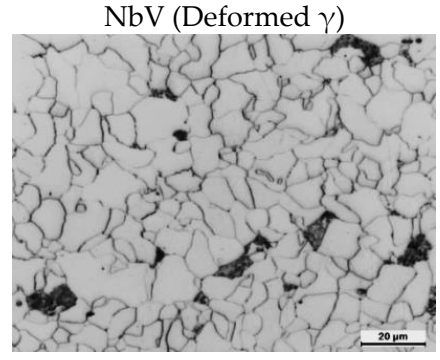

(g) Tdef $25770{ }^{\circ} \mathrm{C}$

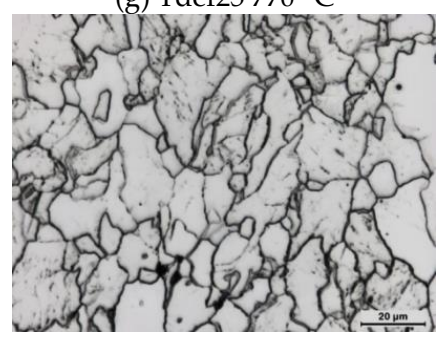

(h) Tdef50 $750{ }^{\circ} \mathrm{C}$

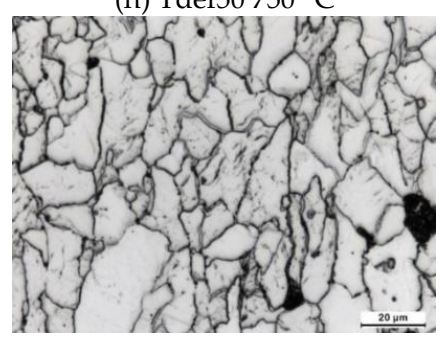

(i) Tdef75 $740{ }^{\circ} \mathrm{C}$

Figure 5. Optical micrographs obtained after air cooling at different deformation temperatures $((\mathbf{a}, \mathbf{d}, \mathbf{g})$ Tdef25, (b,e,h) Tdef50, and (c,f,i) Tdef75) and different conditions: (a,b,c) CMn recrystallized austenite, (d,e,f) $\mathrm{NbV}$ recrystallized austenite, and (g,h,i) $\mathrm{NbV}$ deformed austenite.

With the aim of evaluating the effect of deformation temperature and ferrite fraction before deformation on the final microstructure more precisely, the microstructural analysis was extended via EBSD. The EBSD technique was used to analyze the microstructural features of the samples deformed in the intercritical region, which cannot be correctly quantified by any other standard microstructural characterization techniques such as optical microscopy and/or FEG-SEM. In Figure 6, the grain boundary maps related to the $\mathrm{NbV}$ recrystallized austenite and CMn steels can be compared for Tdef 25 $(\mathrm{a}, \mathrm{c})$ and Tdef75 $(\mathrm{b}, \mathrm{d})$. The boundaries between $2^{\circ}<\vartheta<15^{\circ}$ are considered the low angle boundary, while those with $\vartheta>15^{\circ}$ are assumed to be high angle boundaries [14]. In Figure 6, the low and high angle boundaries are drawn in red and black, respectively. With regard to the effect of chemical composition, it is observed that the addition of $\mathrm{Nb}$ and $\mathrm{V}$ promotes a more intense substructure within the non-deformed ferrite grains (higher fraction of low angle boundaries drawn in red) within the ferrite grains, mainly in the highest ferrite content (see Figure $6 \mathrm{~b}, \mathrm{~d}$ ). This could be related to the effect of microalloying elements (mainly $\mathrm{Nb}$ ) on the delaying of transformation start temperatures. It is known 
that the addition of $\mathrm{Nb}$ retards the austenite to ferrite transformation $[15,16]$, which implies that ferrite will be formed at lower transformation temperatures, leading to the formation of more bainitic phases. Quasipolygonal ferrite grains are characterized by irregular grain boundaries and often show etching evidence of substructure [17].

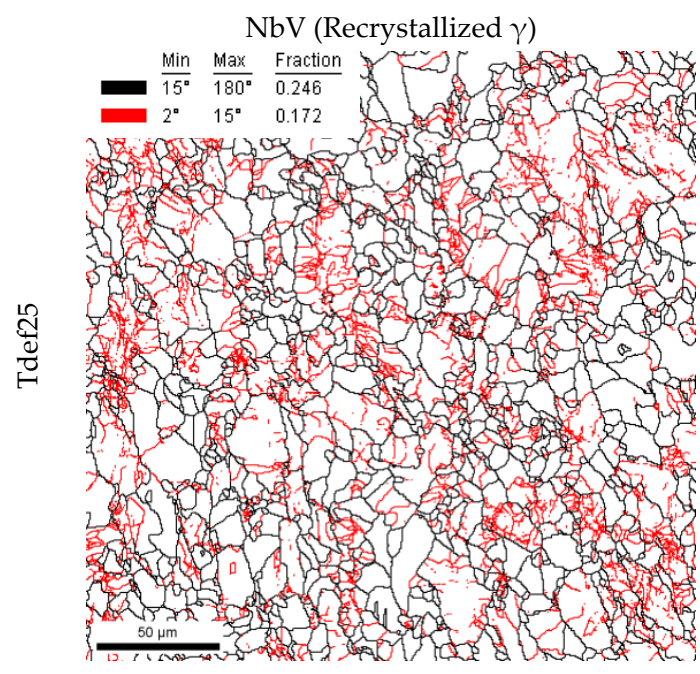

(a)

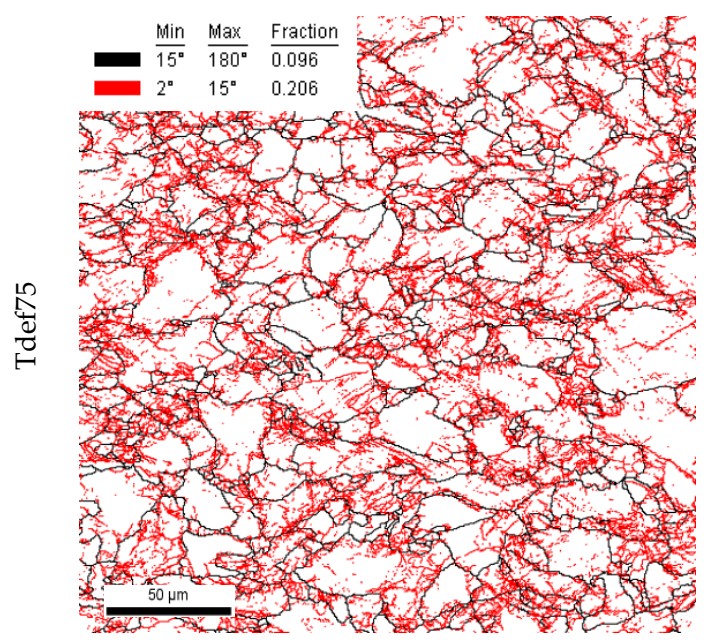

(b)

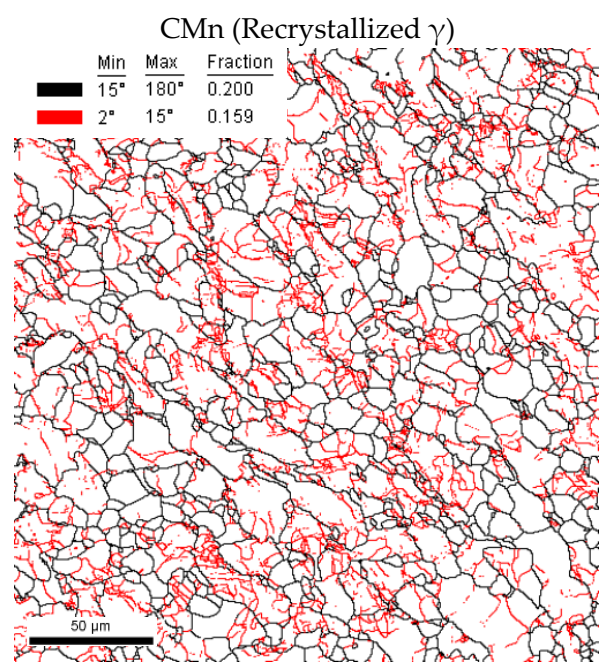

(c)

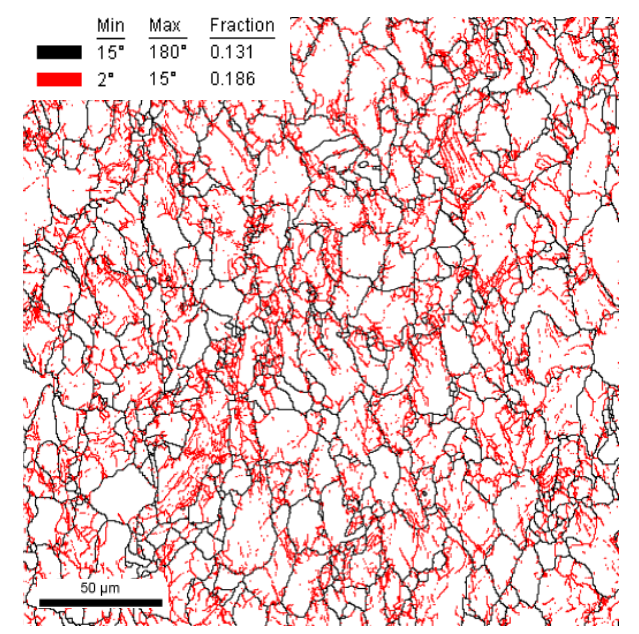

(d)

Figure 6. Grain boundary maps (low and high angle boundaries, in red and black color, respectively) corresponding to $(\mathbf{a}, \mathbf{b}) \mathrm{NbV}$ recrystallized austenite and $(\mathbf{c}, \mathbf{d}) \mathrm{CMn}$. Different ferrite levels prior to deformation have been included: (a,c) Tdef25 and (b,d) Tdef75.

In addition, the EBSD maps shown in Figure 6 suggest that depending on the deformation temperature and, consequently, the fraction of ferrite prior to intercritical deformation, completely different microstructures are formed. When the microstructure contains a low fraction of ferrite prior to intercritical deformation, the presence of relatively polygonal ferrite grains is clearly observed (see Figure $6 \mathrm{a}, \mathrm{c})$. As the deformation temperature decreases, more elongated and coarser grains can be observed. As mentioned before, the applied deformation promotes the modification of the formed ferrite, reflected in the presence of a higher substructure. Figure 6 shows that the deformed ferrite is characterized by a significant presence of substructure, reflected in a higher fraction of low angle boundaries drawn in red. This could be clearly observed for both chemical compositions. In both steels, for Tdef7 5 condition, a lower deformation temperature than in Tdef 25 is applied, leading to the formation of a more intense substructure as the deformation temperature decreases. 
The differences between different ferrite morphologies can be appreciated more properly in the FEG-SEM micrographs shown in Figure 7, which presents the micrographs corresponding to the $\mathrm{NbV}$ steel and the lowest deformation temperatures (Tdef75). Figure 7a corresponds to the microstructure obtained after transformation from recrystallized austenite (Cycle A) and intercritically deformed at $720^{\circ} \mathrm{C}$, whereas in Figure $7 \mathrm{~b}$, the micrograph is related to the sample transformed from deformed austenite (Cycle B) with an intercritical deformation at $740{ }^{\circ} \mathrm{C}$. The addition of microalloying elements, especially $\mathrm{Nb}$, promotes the formation of more bainitic phases and reduces the presence of polygonal phases, leading to non-equiaxed grains being predominant in the microstructure [12]. This quasi-polygonal ferrite is observed in both austenite conditions of the $\mathrm{NbV}$-microalloyed steel. However, the differences between the microstructures formed from recrystallized austenite and deformed austenite are clear. Furthermore, when the transformation occurs from recrystallized austenite (Figure 7a), deformation bands are identified inside the deformed ferrite grains, reflecting a lack of ferrite restoration. The addition of $\mathrm{Nb}$ delays or suppresses the restoration of ferrite when the transformation occurs from Cycle A (recrystallized austenite). The drag effect at low temperatures (ranging between $740{ }^{\circ} \mathrm{C}$ and $720^{\circ} \mathrm{C}$ ), delays and suppresses the restoration of ferrite during intercritical deformation $[2,3]$. However, in the sample transformed from deformed austenite (Figure $7 \mathrm{~b}$ ), there is a substructure composed of subgrains, which is associated with the activation of restoration during the deformation pass [13]. The deformation of austenite below the non-recrystallization temperature $\left(\mathrm{T}_{\mathrm{nr}}\right)$ promotes strain-induced precipitates which are effective for austenite pancaking but reduce the $\mathrm{Nb}$ available during and after transformation to interact with ferrite restoration or recrystallization phenomena [3].

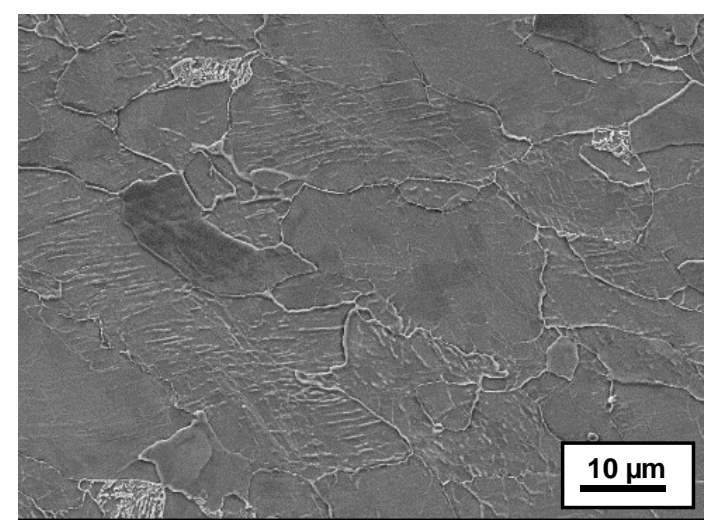

(a)

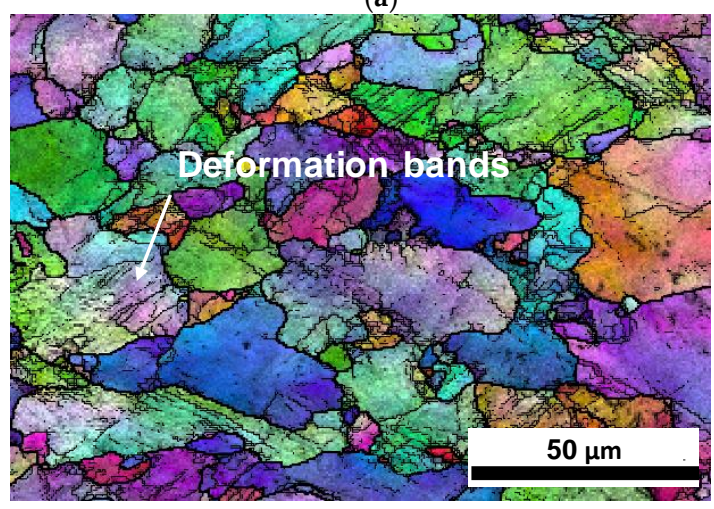

(c)

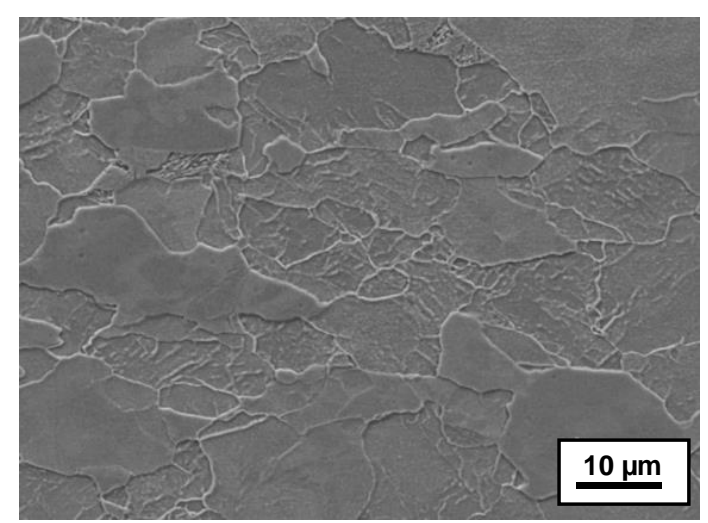

(b)

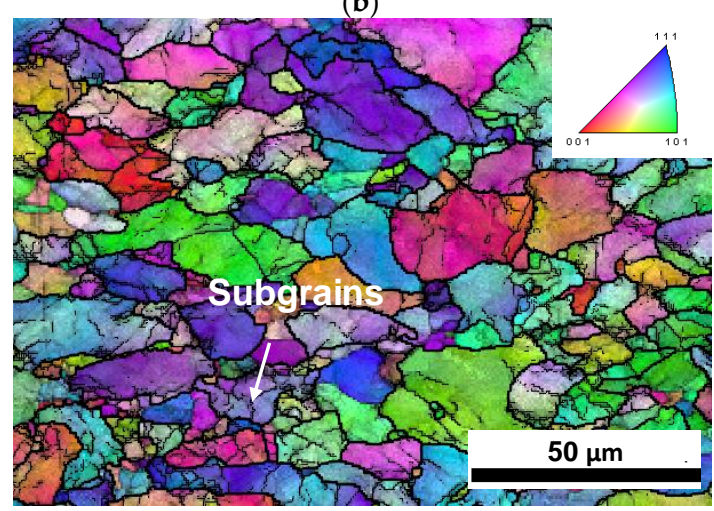

(d)

Figure 7. (a,b) FEG-SEM micrographs and (c,d) inverse pole figure (IPF) + image quality (IQ) maps corresponding to the $\mathrm{NbV}$ and Tdef75: (a,c) Cycle A (transformation from recrystallized austenite) and intercritical deformation temperature of $720^{\circ} \mathrm{C}$ and $(\mathbf{b}, \mathbf{d})$ Cycle B (transformation from deformed austenite) and deformation temperature of $740^{\circ} \mathrm{C}$. 
In Figure $7 \mathrm{c}, \mathrm{d}$, inverse pole figures (IPFs) and image quality maps are superimposed, as are high and low angle boundaries (coarse and fine black lines, respectively). As mentioned previously, a completely different substructure is observed inside the deformed ferrite grains for each austenite condition (see the low angle boundaries drawn in the IPF maps). When the ferrite comes from a deformed austenite, well-defined subgrains are observed in the deformed ferrite (see Figure 7d). By contrast, when the transformation occurs from a recrystallized austenite, the deformed ferrite presents microbands (see Figure $7 \mathrm{c}$ ). The addition of $\mathrm{Nb}$ delays or suppresses the restoration of ferrite when transformation takes place from a recrystallized austenite, promoting the formation of microbands. In the sample transformed from deformed austenite, a clear substructure associated with the activation of restoration during the deformation pass is noticed $[2-5,13]$.

\subsection{Effect of Austenite Conditioning and Addition of Microalloying Elements}

As shown in Figure 5, the microstructures generated after intercritical deformation are composed of different balances of NDF and DF, with some pearlite (P) islands dispersed in the ferritic matrix. In order to analyze the microstructural features of the deformed (DF) and non-deformed ferrite (NDF) populations separately, a recently developed discretization methodology was employed [7].

In the microstructures shown above, three different ferrite populations are identified: polygonal ferrite $(\mathrm{PF})$, quasi-polygonal ferrite $(\mathrm{QF})$, and deformed ferrite. GOS distributions were analyzed in each case, defining a grain tolerance angle of $5^{\circ}$ and a minimum grain size of $0.91 \mu \mathrm{m}$. For each GOS distribution, a threshold GOS value was defined for differentiating deformed and non-deformed ferrite grains and optimum GOS values were defined for obtaining the desired ferrite fraction $(25 \%, 50 \%$, and $75 \%$ ). From this analysis, a common value of $4^{\circ}$ was estimated as the average of all the threshold angles defined in each scan. This threshold GOS value was able to distinguish both non-deformed and deformed ferrite in the final microstructure for both compositions, the ferrite content before deformation, and austenite condition (recrystallized and deformed ferrite). In this case, the ferrite population with GOS values lower than $4^{\circ}$ is considered non-deformed ferrite, where PF and QF are included. GOS values higher than $4^{\circ}$ correspond to deformed ferrite grains. As an example, in Figure 8 , the grain boundary maps corresponding to both non-deformed (polygonal and quasi-polygonal ferrite in Figure 8a) and deformed ferrite families (in Figure $8 b$ ) are shown. The differentiation of both ferrite populations is shown for $\mathrm{CMn}$ steel and a deformation temperature of $740{ }^{\circ} \mathrm{C}$ (Tdef50).

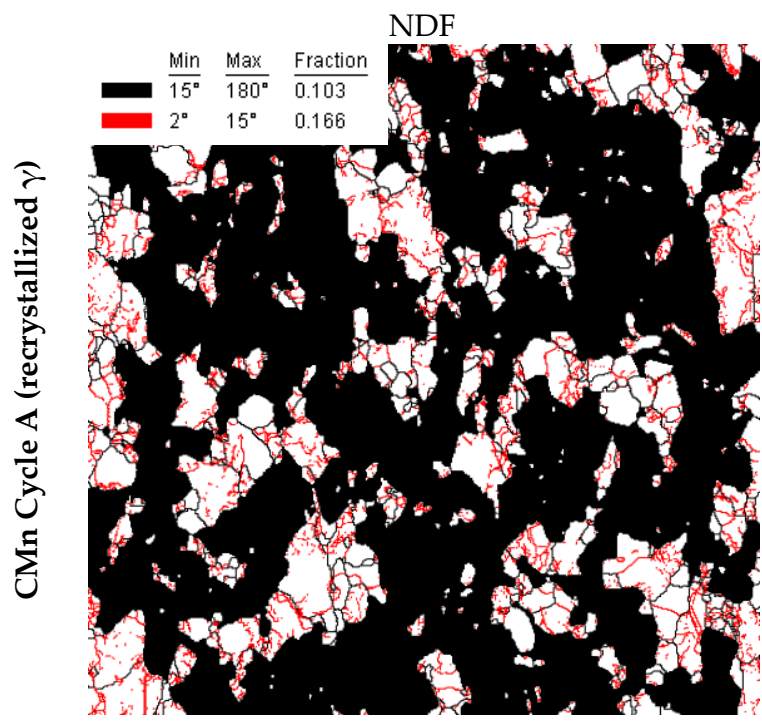

(a)

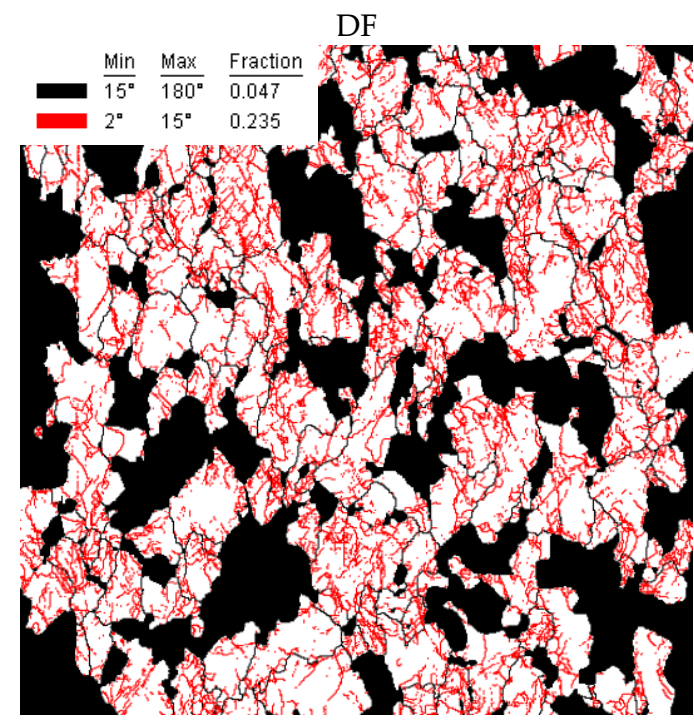

(b)

Figure 8. Grain boundary maps (low and high angle boundaries, in red and black color, respectively) corresponding to Tdef50 and CMn steel: (a) non-deformed ferrite (NDF) and (b) deformed ferrite (DF) family. 
Based on the discretization methodology described above, high angle misorientation unit sizes for each ferrite type were quantified, considering the $15^{\circ}$ misorientation criterion $\left(D_{15^{\circ}}\right)$. The effective grain size was calculated as the equivalent circle diameter corresponding to the individual grain area. The considered minimum grain size is equal to 3 pixels (equivalent to $0.9 \mu \mathrm{m}$ for the $0.5 \mu \mathrm{m}$ step size employed in the current EBSD analysis). In Figure 9a,b, unit size distributions are presented for both non-deformed and deformed ferrite families corresponding to Tdef50. Comparing the grain size distributions obtained in each ferrite population, significantly finer grains were measured for non-deformed ferrite (see Figure 9a) compared to deformed ferrite (Figure 9b). Additionally, in Figure 9c,d, mean grain size values are plotted for both ferrite types and different ferrite levels, as well as both chemistries and austenite conditions. As mentioned previously, in the analysis of the results shown in Figure 9c,d, considerably finer microstructures were obtained in the non-deformed ferrite formed during the final air cooling step. With regard to the mean grain size trends corresponding to non-deformed ferrite population, no significant effect of ferrite fraction before deformation and addition of microalloying elements on grain size is observed. Similar mean unit size values were measured in entire ferrite content for both steels and different austenite conditions. Nevertheless, a different behavior could be detected regarding the evolution of mean grain size of the deformed ferrite family. The addition of $\mathrm{Nb}$ and $\mathrm{V}$ promotes microstructural refinement when the transformation occurs from deformed austenite. In summary, a microstructural refinement is ensured when deformation is accumulated in the austenite prior to transformation. The benefit of the accumulation of deformation in the austenitic range is associated with the increase of the specific grain boundary, which leads to a significant increase in the density of ferrite nucleation sites introduced by deformation [18-21].

Different equations have been proposed in the literature for predicting the ferrite grain size after austenite-to-ferrite transformation for different steels [19,22-24]. All of the mentioned expressions take into account the initial austenite grain size $(d \gamma)$, the cooling rate under continuous cooling conditions $(\dot{T})$, and the accumulated strain in the austenite prior to transformation $\left(\varepsilon_{a c c}\right)$. However, depending on the equation, significant differences can be observed in the predicted ferrite grain size. After comparing the predicted ferrite grain size with the experimental grain size values, the approach proposed by Bengochea et al. [19] (see Equation (1)) was selected.

$$
d_{\alpha}=\left(1-0.5 \varepsilon_{a c c}^{0.47}\right)\left(4.5+3 \dot{T}^{-\frac{1}{2}}+13.4\left(1-\exp \left(-0.015 d_{\gamma}\right)\right)\right),
$$

where $d \gamma, \varepsilon_{a c c}$, and $\dot{T}$ are the austenite mean grain size (in $\mu \mathrm{m}$ ), the accumulated strain in the austenite prior to transformation, and the cooling rate $\left({ }^{\circ} \mathrm{C} / \mathrm{s}\right)$, respectively.

Even though Equation (1) [19] was initially developed for continuous cooling conditions (austenite-ferrite phase transformation), in the present work, the applicability of this approach for intercritically deformed microstructure was evaluated. Considering this equation, the intercritically deformed ferrite grain size, as well as the non-deformed ferrite grain size were predicted. In Table 3, besides the predicted mean ferrite grain sizes, the variables considered in each condition are summarized for both ferrite families. For the deformed ferrite population (DF), the mean austenite grain size at $1050{ }^{\circ} \mathrm{C}$ is considered (after the deformation pass at this temperature) (73 and $55 \mu \mathrm{m}$, for CMn and $\mathrm{NbV-microalloyed} \mathrm{steel,} \mathrm{respectively).} \mathrm{In} \mathrm{the} \mathrm{NbV}$ deformed austenite condition, an accumulated strain $\left(\varepsilon_{a c c}\right)$ of 0.4 was considered in order to take into account the accumulation of deformation in the austenite prior to transformation. In analyzing the predicted mean ferrite grain sizes, it is observed that finer ferrite grains are estimated for $\mathrm{NbV}$ deformed austenite.

Regarding the non-deformed ferrite grain size (transformed after intercritical deformation and during the final air cooling step), the $\varepsilon_{a c c}$ term is considered to be 0.4 for $\mathrm{CMn}$ and $\mathrm{NbV}$ recrystallized austenite, whereas for $\mathrm{NbV}$ deformed austenite, a $\varepsilon_{a c c}$ of 0.8 is taken into account (the sum of the deformation applied below $\mathrm{T}_{\mathrm{nr}}$ in austenite and deformation applied in the intercritical region). To estimate mean austenite grain size prior to transformation, the ferrite content prior to intercritical deformation must be taken into account $[25,26]$. It is well known that as ferrite content increases before 
deformation, the remaining austenite grain size decreases. Therefore, the remaining austenite sizes were measured in selected quenched samples prior to intercritical deformation (by measuring the martensitic regions in the quenched samples) in order to find the relation between ferrite fraction before intercritical deformation and the remaining austenite size. For example, in the $\mathrm{NbV}$ recrystallized austenite condition, the mean austenite size decreased from 47 to $26 \mu \mathrm{m}$, increasing the intercritically deformed ferrite fraction from $24 \%$ to $71 \%$. As the content of ferrite prior to intercritical deformation increased, the predicted mean non-deformed ferrite size decreased, due to the reduction of the mean austenite grain size. For example, for $\mathrm{NbV}$ recrystallized austenite, calculated $\mathrm{d} \alpha$ decreased from 9.6 to $8.0 \mu \mathrm{m}$ when the ferrite fraction increased from $24 \%$ to $71 \%$.

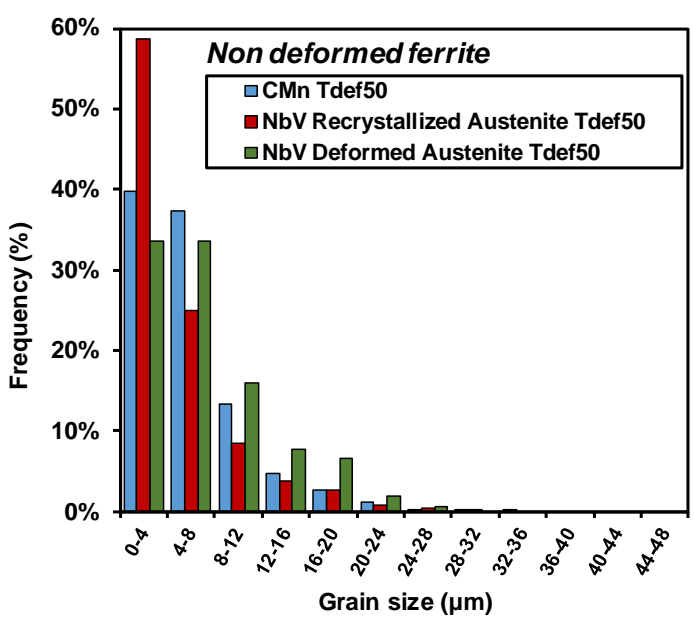

(a)

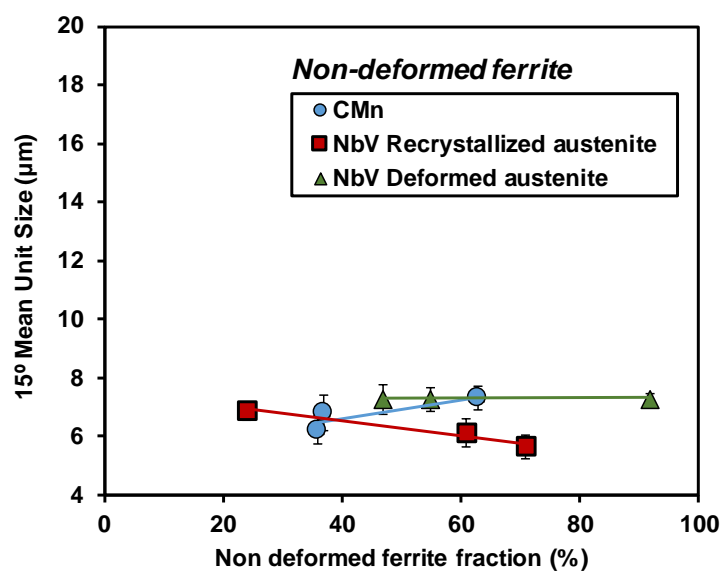

(c)

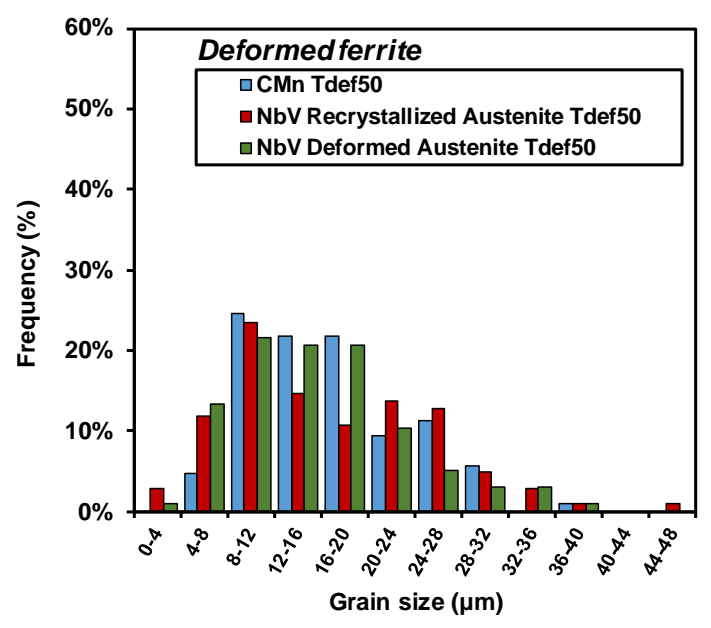

(b)

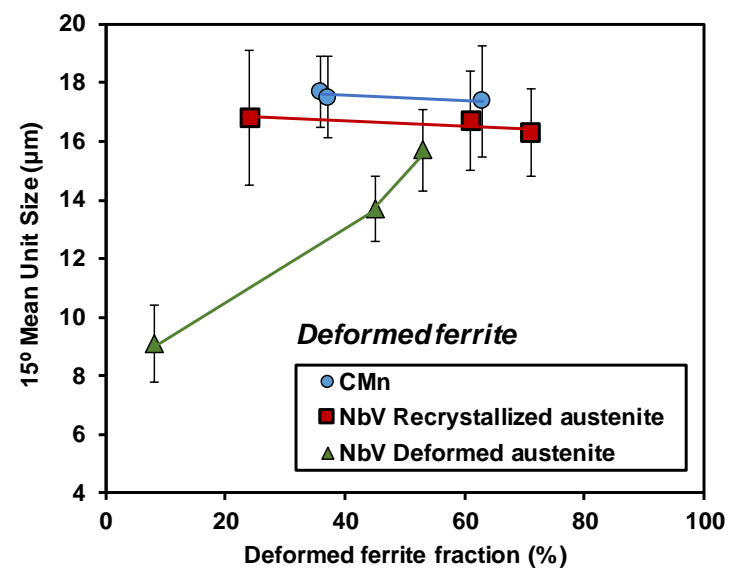

(d)

Figure 9. Grain size distributions corresponding to Tdef50 and different chemical composition (CMn, $\mathrm{NbV}$ recrystallized austenite, and $\mathrm{NbV}$ deformed austenite): (a) Non-deformed ferrite and (b) deformed ferrite population. Influence of austenite/ferrite balance, chemical composition, and austenite condition on $15^{\circ}$ mean grain size of both ferrite populations: (c) non-deformed ferrite and (d) deformed ferrite population. 
Table 3. Predicted mean ferrite grain sizes for both ferrite families considering Equation (1) [19] and the variables considered in each condition.

\begin{tabular}{|c|c|c|c|c|c|c|}
\hline Ferrite Family & Condition & $\begin{array}{l}\text { Ferrite Content Prior } \\
\text { to Deformation (\%) }\end{array}$ & $\begin{array}{c}\text { Mean Austenite Size, } \\
\qquad d \gamma(\mu \mathrm{m})\end{array}$ & $\varepsilon_{a c c}$ & $\begin{array}{c}\dot{T} \\
\left({ }^{\circ} \mathrm{C} / \mathrm{s}\right)\end{array}$ & $\begin{array}{c}d \alpha \text { Predicted }(\mu \mathrm{m}) \text { by } \\
\text { Equation (1) }\end{array}$ \\
\hline \multirow{9}{*}{ DF } & \multirow{3}{*}{$\mathrm{CMn}$} & 37 & 73 & 0 & 1 & 16.4 \\
\hline & & 64 & 73 & 0 & 1 & 16.4 \\
\hline & & 63 & 73 & 0 & 1 & 16.4 \\
\hline & \multirow{3}{*}{$\begin{array}{l}\mathrm{NbV} \\
\text { recrystallized } \\
\text { austenite }\end{array}$} & 24 & 55 & 0 & 1 & 15 \\
\hline & & 61 & 55 & 0 & 1 & 15 \\
\hline & & 71 & 55 & 0 & 1 & 15 \\
\hline & \multirow{3}{*}{$\begin{array}{l}\mathrm{NbV} \text { deformed } \\
\text { austenite }\end{array}$} & 8 & 55 & 0.4 & 1 & 10.1 \\
\hline & & 53 & 55 & 0.4 & 1 & 10.1 \\
\hline & & 45 & 55 & 0.4 & 1 & 10.1 \\
\hline \multirow{9}{*}{ NDF } & \multirow{3}{*}{$\mathrm{CMn}$} & 37 & 36 & 0.4 & 1 & 8.9 \\
\hline & & 64 & 16 & 0.4 & 1 & 7.0 \\
\hline & & 63 & 16 & 0.4 & 1 & 7.0 \\
\hline & \multirow{3}{*}{$\begin{array}{c}\mathrm{NbV} \\
\text { recrystallized } \\
\text { austenite }\end{array}$} & 24 & 47 & 0.4 & 1 & 9.6 \\
\hline & & 61 & 31 & 0.4 & 1 & 8.4 \\
\hline & & 71 & 26 & 0.4 & 1 & 8.0 \\
\hline & \multirow{3}{*}{$\begin{array}{l}\mathrm{NbV} \text { deformed } \\
\text { austenite }\end{array}$} & 8 & 52 & 0.8 & 1 & 8.1 \\
\hline & & 53 & 35 & 0.8 & 1 & 7.1 \\
\hline & & 45 & 38 & 0.8 & 1 & 7.3 \\
\hline
\end{tabular}

In Figure 10, the predicted ferrite sizes are plotted as a function of ferrite grain size measured by the EBSD technique for the different compositions, austenite conditions, and ferrite families (DF and NDF, deformed and non-deformed ferrite, respectively). With regard to the non-deformed ferrite, a reasonable fitting can be observed for all the conditions. However, for the NDF population, the experimentally measured mean grain sizes were slightly larger than the predicted ferrite grain sizes, principally for the $\mathrm{NbV}$ deformed austenite sample. This deviation is more significant for Tdef50 Tdef75 conditions. For $\mathrm{NbV}$ grade, further analysis is required in order to understand the effect of deformation temperature on ferrite grain size when the transformation takes place from a deformed austenite.

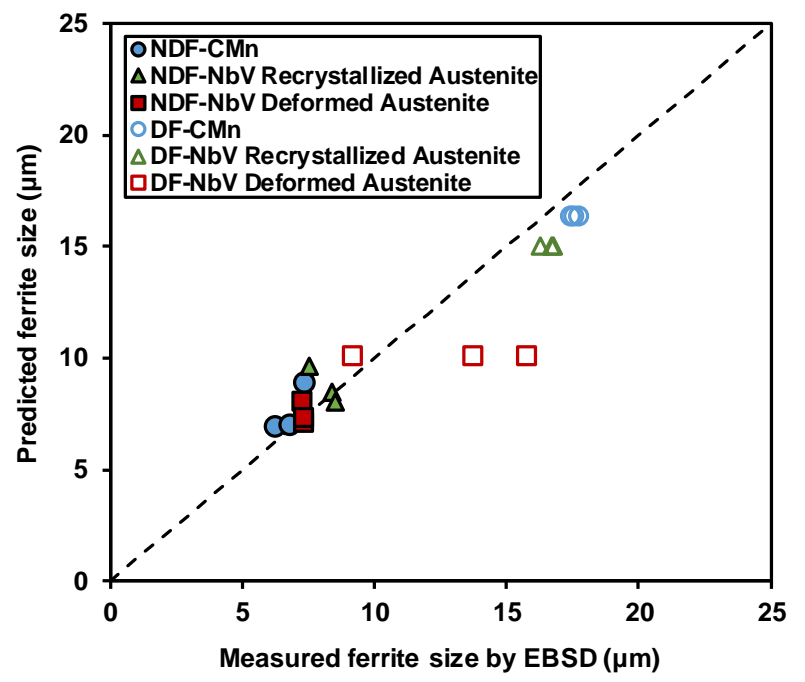

Figure 10. Predicted ferrite grain sizes considering Bengochea's [19] equation as a function of ferrite size measured by EBSD for both chemical composition, austenite conditions, and both ferrite populations (NDF and DF).

\subsection{Interaction between Precipitation, $\mathrm{Nb}$ in Solution, and Intercritically Deformed Ferrite}

In order to evaluate the role of $\mathrm{Nb}$ and $\mathrm{V}$ precipitates in the different processes (restoration, recrystallization) occurring during the intercritical rolling, a study of fine precipitates was carried out on carbon extraction replicas, and the average precipitate size was measured in selected conditions. Figure 11 shows differences in precipitation for both recrystallized and deformed austenite for the 
Tdef75 condition. Regarding the effect of austenite conditioning, different precipitation populations were formed depending on the applied rolling strategy (recrystallized or deformed austenite). When the transformation occurs from recrystallized austenite, a high density of fine precipitates can be detected. These precipitates are considered to be formed in ferrite during or after the intercritical deformation. Nevertheless, in the sample corresponding to deformed austenite, strain-induced precipitates formed in austenite are also observed. In all cases, most of the particles are $\mathrm{Nb}$-rich precipitates, as well as $\mathrm{NbV}$ and $\mathrm{NbTiV}$-rich precipitates (see microanalysis shown in Figure 11e).

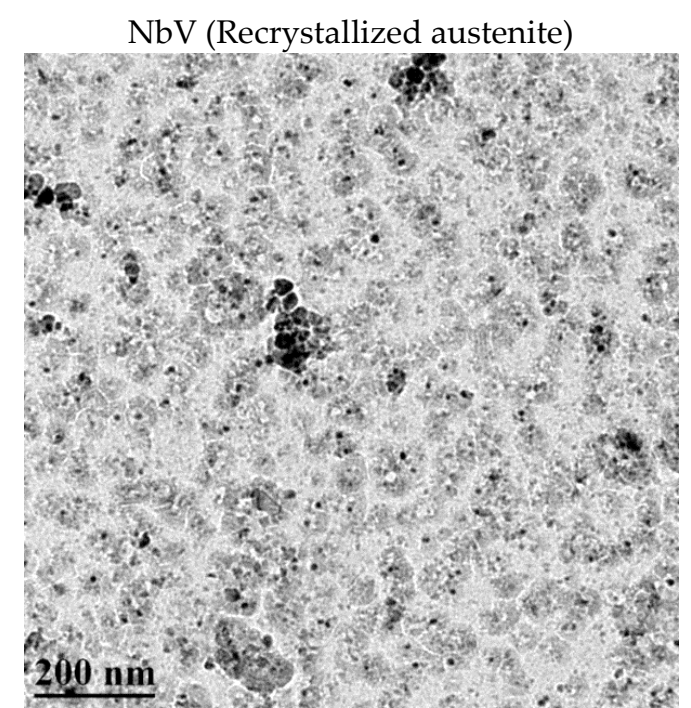

(a)

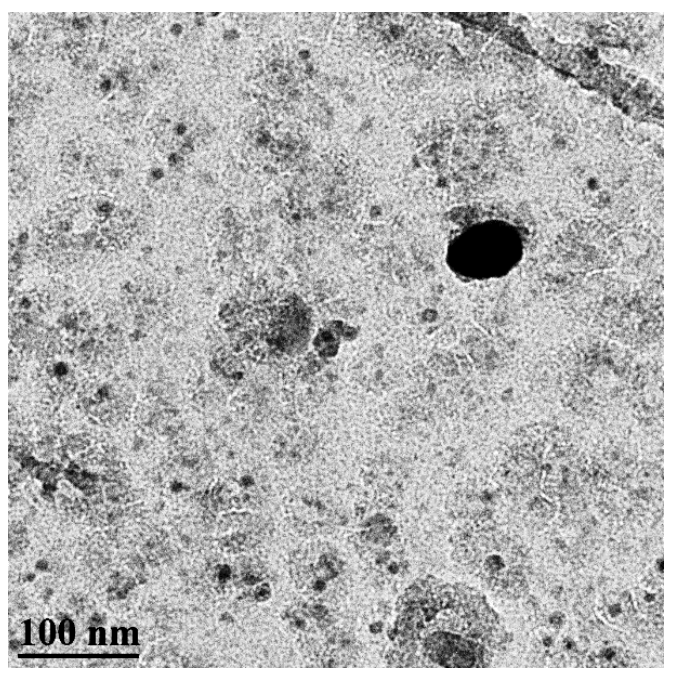

(b)

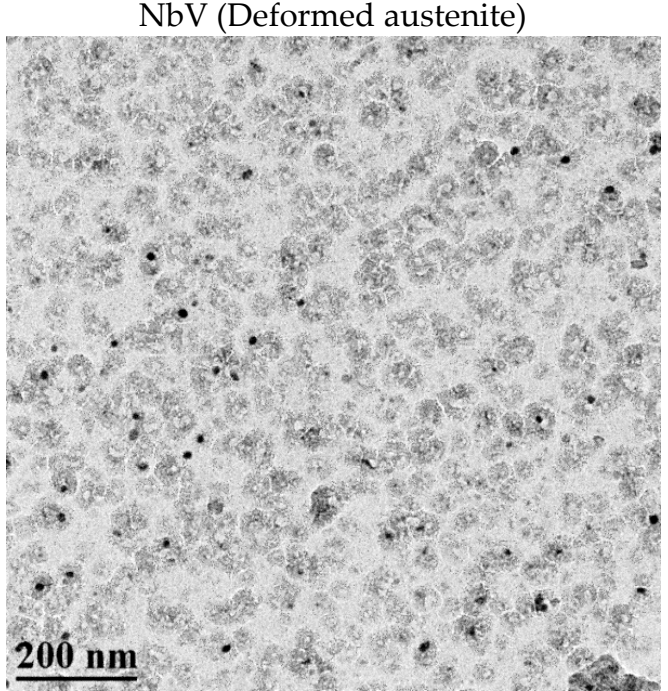

(c)

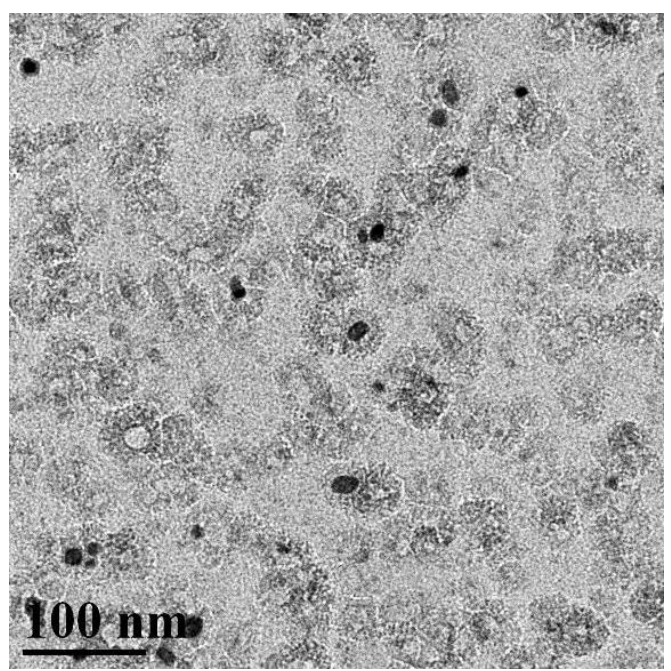

(d)

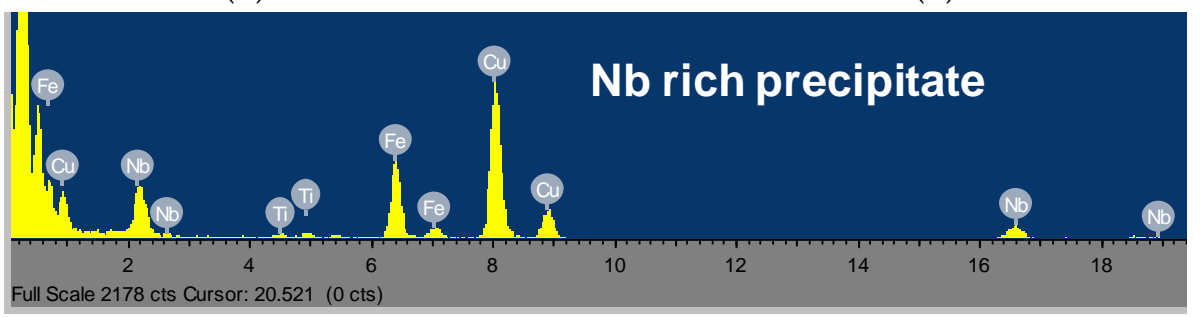

(e)

Figure 11. TEM images obtained in $(\mathbf{a}, \mathbf{b}) \mathrm{NbV}$ recrystallized austenite and (c,d) $\mathrm{NbV}$ deformed austenite at different magnifications for Tdef75. (e) Microanalysis of the precipitates. 
In Figure 12a, the precipitate size distributions are plotted. The precipitate diameter distributions corresponding to recrystallized austenite and deformed austenite conditions (Tdef75 case) can be compared. The results indicate that noticeably finer precipitates were measured when transformation occurs from recrystallized austenite (mean precipitate size is decreased from 15.9 to $10.2 \mathrm{~nm}$ ). This could be related to the fact that a lower intercritical deformation temperature is applied in Cycle A (recrystallized austenite), which leads to the formation of finer precipitates in ferrite. In addition, as previously mentioned, a higher density of fine precipitates was observed.

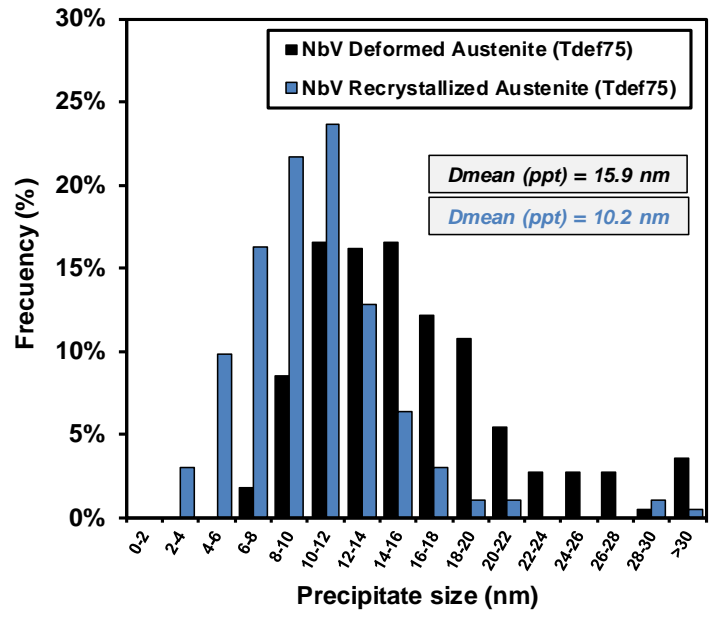

(a)

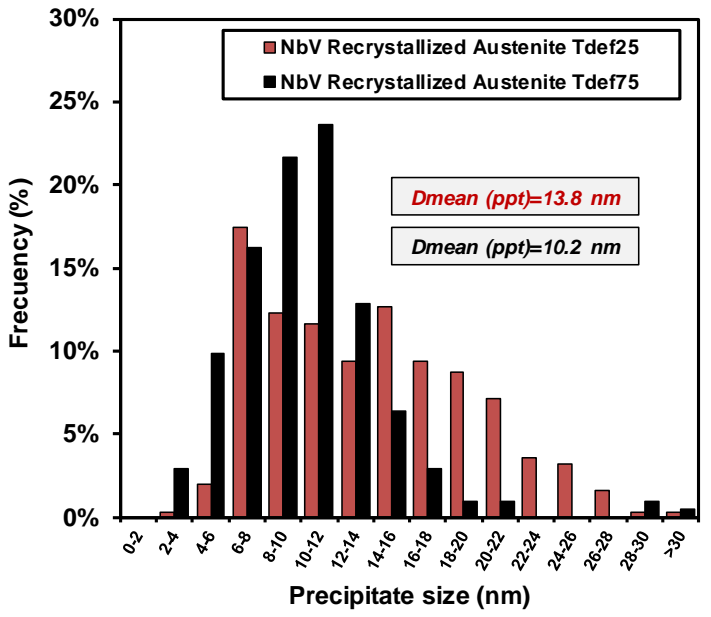

(b)

Figure 12. Precipitate size distribution measured for (a) $\mathrm{NbV}$ recrystallized austenite and $\mathrm{NbV}$ deformed austenite for Tdef75. (b) Tdef25 and Tdef75 for NbV recrystallized austenite.

The results indicate that the nanometric precipitates could suppress the restoration of ferrite, forming microbands when transformation occurs from recrystallized austenite. In the case of Cycle B (deformed austenite), strain-induced precipitates formed in the austenitic region-which are bigger but fewer in number-were not able to stop the restoration process that happens during or after the intercritical deformation. Differences in the niobium available during transformation are a key factor in maintaining the deformation bands or in developing a substructure within the intercritically deformed ferrite grains.

Besides the analysis of the influence of the accumulation of deformation in the austenite prior to transformation, the effect of ferrite fraction before intercritical deformation was also analyzed. An example is given in Figure 13, which shows the comparison between TEM images corresponding to Tdef 25 and Tdef75. Furthermore, in Figure 12b, the precipitate size distributions are also presented. Quantified mean precipitate sizes are also included in the graphs. A significant precipitate size refinement is clearly noticeable as ferrite content prior to deformation increases and intercritical deformation temperature decreases. Moreover, as shown in Figure 13, a higher fraction of fine precipitates is observed for Tdef75. Mean precipitate size decreases from 13.8 to $10.2 \mathrm{~nm}$ when the fraction of ferrite before intercritical deformation increases from $25 \%$ to $75 \%$. Finer precipitates are formed when lower intercritical deformation is applied, confirming that the precipitation occurs during or after intercritical deformation. 


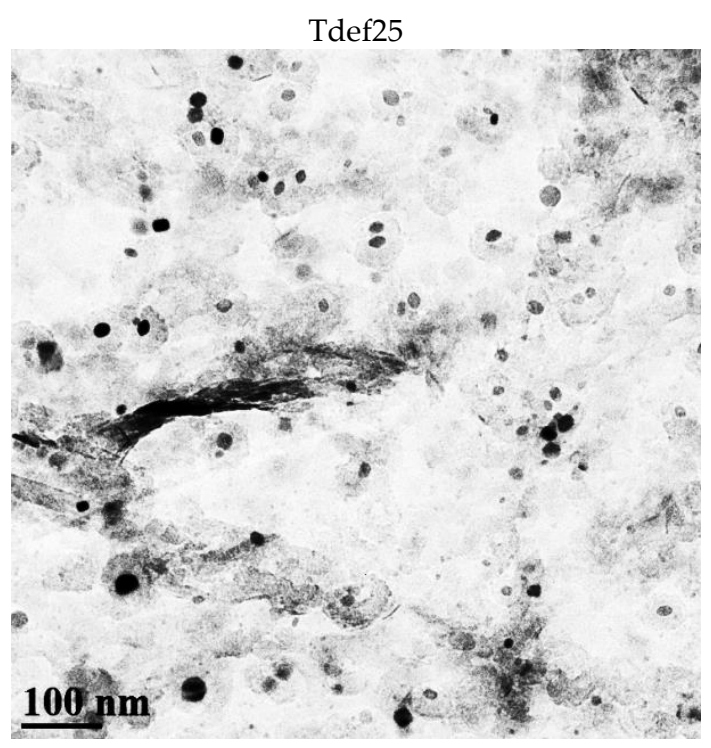

(a)

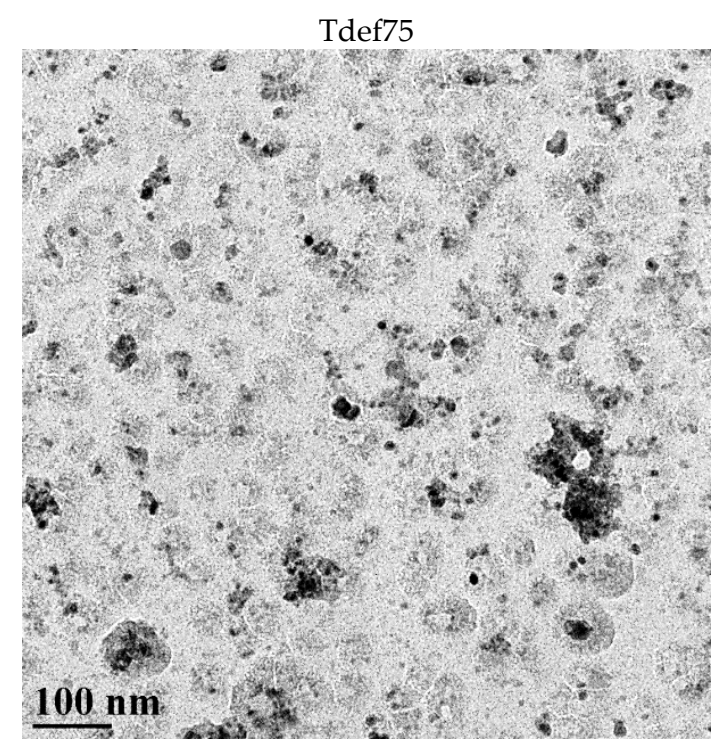

(b)

Figure 13. TEM images obtained in $\mathrm{NbV}$ recrystallized austenite and different ferrite contents prior to intercritical deformation: (a) Tdef25 and (b) Tdef75.

\section{Conclusions}

The analysis of intercritically deformed microstructures has been validated and extended to $\mathrm{NbV-microalloyed} \mathrm{steels} \mathrm{following} \mathrm{an} \mathrm{EBSD} \mathrm{characterization} \mathrm{procedure.} \mathrm{The} \mathrm{threshold} \mathrm{values} \mathrm{for}$ differentiating between deformed and non-deformed ferrite depend on the ferritic structure formed. Non-deformed equiaxed ferrite grains can be distinguished more easily from deformed ferrite grains, while in situations where non-polygonal and more bainitic structures are formed, the differentiation between deformed and non-polygonal grains is more diffuse due to a higher dislocation density in the latter.

The transformation of ferrite from recrystallized and deformed austenite implies modifications in the intercritically deformed ferrite. Differences in the niobium available during transformation are a key factor in maintaining the deformation bands and in developing a substructure within the intercritically deformed grains.

Author Contributions: U.M. carried out the experiments and wrote the manuscript; N.I. analyzed the data and wrote the manuscript; J.M.R.-I. supervised the results and edited the manuscript; P.U. managed the project and edited the manuscript.

Funding: This research was funded by Spanish Ministry of Economy and Competitiveness (MAT2015-69752) and by the European Commission Research Fund for Coal and Steel (RFSR-CT-2015-00014).

Conflicts of Interest: The authors declare no conflict of interest.

\section{References}

1. Humphreys, A.O.; Liu, D.; Toroghinejad, M.R.; Essadiqi, E.; Jonas, J.J. Warm rolling behaviour of low carbon steels. Mater. Sci. Technol. 2003, 19, 709-714. [CrossRef]

2. Simielli, E.A.; Yue, S.; Jonas, J.J. Recrystallization kinetics of microalloyed steels deformed in the intercritical region. Met. Trans. A 1992, 23, 597-608. [CrossRef]

3. Kwon, O.; De Ardo, A.J. Interactions between recrystallization and precipitation in hot-deformed microalloyed steels. Acta Mater. 1991, 39, 529-538. [CrossRef]

4. Dunne, D.P.; Feng, B.; Chandra, T. The effect of Ti and Ti-Nb additions on $\alpha$ formation and restoration during intercritical rolling and holding of C-Mn structural steels. ISIJ Int. 1991, 31, 1354-1361. [CrossRef]

5. Smith, A.; Luo, H.; Hanlon, D.N.; Sietsma, J.; Van Der Zwaag, S. Recovery processes in the ferrite phase in C-Mn steel. ISIJ Int. 2004, 44, 1188-1194. [CrossRef] 
6. Eghbali, B. Microstructural development in a low carbon Ti microalloyed steel during deformation within the ferrite region. Mat. Sci. Eng. A 2008, 480, 84-88. [CrossRef]

7. Mayo, U.; Isasti, N.; Jorge-Badiola, D.; Rodriguez-Ibabe, J.M.; Uranga, P. An EBSD-based methodology for the characterization of intercritically deformed low carbon steel. Mat. Charact. 2019, 147, 31-42. [CrossRef]

8. Wright, S.I.; Nowell, M.M. EBSD image quality mapping. Microsc. Microanal. 2006, 12, 72-84. [CrossRef] [PubMed]

9. Llanos, L.; Pereda, B.; Jorge-Badiola, D.; Rodriguez-Ibabe, J.M.; López, B. Study of recrystallization in high manganese steels by means of the EBSD technique. Mat. Sci. Forum 2013, 753, 443-448. [CrossRef]

10. Olasolo, M.; Uranga, P.; Rodriguez-Ibabe, J.M.; López, B. Effect of austenite microstructure and cooling rate on transformation characteristics in a low carbon $\mathrm{Nb}-\mathrm{V}$ microalloyed Steel. Mater. Sci. Eng. A 2011, 528, 2559-2569. [CrossRef]

11. Bengochea, R.; Lopez, B.; Gutierrez, I. Microstructural evolution during the austenite-to-ferrite transformation from deformed austenite. Metall. Mater. Trans. A 1998, 29, 417-426. [CrossRef]

12. Petrov, R.; Kestens, L.; Houbaert, Y. Characterization of the microstructure and transformation behaviour of strained and nonstrained austenite in Nb-V-alloyed C-Mn steel. Mater. Charact. 2004, 53, 51-61. [CrossRef]

13. American Society for Testing and Materials (ASTM). ASTM E-562 Standard Test Method for Determining Volume Fraction by Systematic Manual Point Count; ASTM International: West Conshohocken, PA, USA, 2019.

14. Isasti, N.; Jorge-Badiola, D.; Taheri, M.L.; López, B.; Uranga, P. Effect of composition and deformation on coarse-grained austenite transformation in nb-mo microalloyed steels. Met. Trans. A 2011, 42, 3729-3742. [CrossRef]

15. Isasti, N.; Jorge-Badiola, D.; Taheri, M.L.; Uranga, P. Phase transformation study in Nb-Mo microalloyed steels using dilatometry and EBSD quantification. Metall. Mater. Trans. A 2013, 44, 3552-3563. [CrossRef]

16. Cizek, P.; Wynne, B.P.; Davies, C.H.J.; Muddle, B.C.; Hodgson, P.D. Effect of composition and austenite deformation on the transformation characteristics of low-carbon and ultralow-carbon microalloyed steels. Met. Trans. A 2002, 33, 1331-1349. [CrossRef]

17. Krauss, G.; Thompson, S.W. Ferritic microstructures in continuously cooled low- and ultralow-carbon steels. ISIJ Int. 1995, 35, 937-945. [CrossRef]

18. Bengochea, R.; López, B.; Gutierrez, I. Influence of the prior austenite microstructure on the transformation products obtained for C-Mn-Nb steels after continuous cooling. ISIJ Int. 1999, 39, 583-591. [CrossRef]

19. Cizek, P.; Wynne, B.P.; Davies, C.H.J.; Hodgson, P.D. The effect of simulated thermomechanical processing on the transformation behavior and microstructure of a low-carbon mo-nb linepipe steel. Met. Trans. A 2015, 46, 407-425. [CrossRef]

20. Tamura, I.; Sekine, H.; Tanaka, T.; Ouchi, C. Thermomechanical Processing of High-Strength Low-Alloy Steels; Butterworth and Company: London, UK, 1988.

21. Speich, G.R.; Cuddy, L.J.; Gordon, C.R.; DeArdo, A.J. Phase Transformations in Ferrous Alloys; Marder, A.R., Goldstein, J.I., Eds.; TMS-AIME: Warrendale, PA, USA, 1983; pp. 341-389.

22. Sellars, C.M.; Beynon, J.H. Proceedings of the Conference on High Strength Low Alloy Steels; Dunee, D., Chandra, T., Eds.; South Coast Printers: Wollongong, Australia, 1984; p. 142.

23. Gibbs, R.K.; Parker, B.A.; Hodgson, P. Low-carbon steels for the 90's. In Proceedings of the International Symposium on Low-Carbon Steels for the 90s; Asfahani, R., Tiher, G., Eds.; The Minerals, Metals and Materials Society: Pittsburgh, PA, USA, 1993; p. 173.

24. García-Riesco, P.M.; Uranga, P.; López, B.; Rodriguez-Ibabe, J.M. Modelling the austenite to ferrite phase transformation in low carbon microalloyed steels in terms of grain size distributions. In Proceedings of the International Conference on Solid-Solid Phase Transformations in Inorganic Materials 2015, PTM'2015, Whistler, BC, Canada, 28 June-3 July 2015; pp. 917-924.

25. Hernandez, D.; López, B.; Rodriguez-Ibabe, J.M. Ferrite grain size refinement in vanadium microalloyed structural steels. Mater. Sci. Forum 2015, 500, 411-418. [CrossRef]

26. Vandermerr, R.A.; Juul Jensen, D. Microstructural path and temperature dependence of recrystallization in commercial aluminum. Acta Mater. 2001, 49, 2083-2094. [CrossRef] 